\title{
Chlorogenic acid prevents inflammatory responses in IL-1 $\beta$-stimulated human SW-1353 chondrocytes, a model for osteoarthritis
}

\author{
CUI-CUI LIU ${ }^{1,2}$, YANMIN ZHANG ${ }^{2}$, BING-LING DAI ${ }^{2}$, \\ YU-JIAO MA ${ }^{2}$, QIAN ZHANG ${ }^{1}$, YI WANG ${ }^{1}$ and HAO YANG ${ }^{1}$ \\ ${ }^{1}$ Translational Medicine Center, Hong-Hui Hospital, Xi'an Jiaotong University College of Medicine; \\ ${ }^{2}$ Department of Pharmacy, School of Medicine, Xi'an Jiaotong University, Xi'an, Shaanxi 710054, P.R. China
}

Received March 29, 2016; Accepted March 28, 2017

DOI: $10.3892 / \mathrm{mmr} .2017 .6698$

\begin{abstract}
Chlorogenic acid (CGA), which is a natural compound found in various plants, has been reported to exert notable anti-inflammatory activities. The present study investigated the effects and underlying mechanism of CGA on interleukin (IL)-1 $\beta$-induced osteoarthritis (OA) chondrocytes. An in vitro OA-like chondrocyte model was established using IL-1 $\beta$-stimulated human SW-1353 chondrocytes. Cell viability was assessed using an MTT assay. Nitric oxide (NO) and IL-6 production were evaluated by Griess reaction and ELISA, respectively. The expression levels of inducible nitric oxide synthase (iNOS), prostaglandin $\mathrm{E}_{2}\left(\mathrm{PGE}_{2}\right)$, cyclooxygenase 2 (COX-2), collagen II, matrix metalloproteinase (MMP)-13, p65 nuclear factor (NF)- $\kappa B$ and inhibitor- $\kappa \mathrm{B} \alpha$ were detected by western blot analysis. The results indicated that CGA reversed IL-1 $\beta$-induced increases in iNOS/NO, IL-6, MMP-13 and $\mathrm{COX}-2 / \mathrm{PGE}_{2}$ production, and reversed the IL-1 $\beta$-mediated downregulation of collagen II. In addition, the data suggested that CGA was capable of inhibiting the IL-1 $\beta$-induced inflammatory response, at least partially via the NF- $\kappa \mathrm{B}$ signaling pathway. In conclusion, CGA may be considered a suitable candidate agent in the treatment of OA.
\end{abstract}

\section{Introduction}

Osteoarthritis (OA) is a common disease of the elderly worldwide, which is characterized by articular cartilage destruction and local inflammation, resulting in pain, disability and a significantly reduced quality of life for the affected individuals (1). Accumulating evidence $(2,3)$ has indicated that

Correspondence to: Dr Hao Yang, Translational Medicine Center, Hong-Hui Hospital, Xi'an Jiaotong University College of Medicine, 555 Youyi Road, Beilin, Xi'an, Shaanxi 710054, P.R. China

E-mail: yanghao.71_99@yahoo.com

Key words: chlorogenic acid, osteoarthritis, cytokines, interleukin- $1 \beta$, nuclear factor- $\kappa \mathrm{B}$ low-grade systemic and local inflammation is involved in the progression of OA (4). Several inflammatory mediators, such as interleukin (IL)-1 $\beta$, nitric oxide (NO), prostaglandin $E_{2}$ $\left(\mathrm{PGE}_{2}\right)$ and fragments of cartilage proteins including matrix metalloproteinases (MMPs), have been reported to be elevated in patients with OA (5). IL-1 $\beta$ is an important proinflammatory cytokine during the inflammatory response, which has been reported to serve critical roles in joint inflammation and cartilage destruction processes. For example, IL-1 $\beta$ elevates NO production, improves cyclooxygenase-2 (COX-2) activity and upregulates the expression of MMPs, including MMP-13, which is associated with extracellular matrix (ECM) degradation in cartilage $(6,7)$. Based on the significant role of inflammation in OA, anti-inflammatory treatment may have significant value in the treatment of OA.

Previous research has also indicated that IL-1 $\beta$, or other certain stimuli including tumor necrosis factor (TNF)- $\alpha$ or lipopolysaccharide (LPS), may activate nuclear factor $(\mathrm{NF})-\kappa \mathrm{B}(8)$, which regulates the expression of several other proinflammatory cytokines and proteases, and mediates critical events in the inflammatory responses of chondrocytes (9). Under normal physiological circumstances, $N F-\kappa B$ is sequestered and bound to its inhibitory protein, inhibitor- $\kappa \mathrm{B} \alpha$ $(\mathrm{I} \kappa \mathrm{B} \alpha)$. When inflammation is induced, I $\mathrm{I} \mathrm{B} \alpha$ undergoes proteasomal degradation. This event is followed by translocation of cytoplasmic NF- $\kappa \mathrm{B}$ into the nucleus, where it activates transcription of numerous proinflammatory cytokines, adhesion molecules and inflammatory mediators, such as inducible nitric oxide synthase (iNOS), TNF- $\alpha$ and MMPs.

Chlorogenic acid (CGA; Fig. 1) is formed from the esterification of caffeic acid and quinic acid, and is a polyphenolic compound isolated from numerous plants, including coffee beans (10), Lonicerae japonicae (11) and Eucommiae cortex (12). Previous studies based on in vivo and in vitro systems have revealed that CGA exerts antioxidant (13), antibacterial (14) and antitumor activities (15). Furthermore, CGA has demonstrated protective effects against several experimental disorders, including mastitis (16), gastroesophageal reflux disease (17) and LPS-induced acute lung injury (18) via downregulation of the inflammatory response. These findings suggested that CGA may serve as a novel therapeutic agent 
for the treatment of inflammatory diseases. Notably, in vitro studies have demonstrated that CGA attenuates the production of several inflammatory mediators, including IL-1 $\beta$, IL-6 and TNF- $\alpha$ in LPS-stimulated RAW264.7 cells (19). In addition, Lee et al demonstrated the anticandidal and anti-arthritic effects of CGA by inhibiting the synthesis of NO in LPS-activated macrophages (20). CGA may also decrease osteoclast differentiation and bone resorption in vivo and may have therapeutic potential in treating diseases associated with inflammatory bone destruction (21). Studies have addressed the therapeutic potential of CGA on arthritis; however, its ability to protect against IL-1 $\beta$-induced OA remains poorly understood.

Human SW-1353 chondrosarcoma cells stimulated with IL-1 $\beta$ possess similar properties to the articular chondrocytes of OA (6). The present study employed this OA-like chondrocyte cellular model as an in vitro tool, in order to investigate the effects of CGA on the expression levels of iNOS/NO, IL-6, $\mathrm{COX}-2 / \mathrm{PGE}_{2}$, collagen II/MMP-13 and NF- $\kappa \mathrm{B}$ signaling pathways. The results indicated that CGA may be of clinical value in the treatment of OA.

\section{Materials and methods}

Chemicals and reagents. CGA (purity $>98 \%$ ) was purchased from Beijing Dewei Sodium Biotechnology Co., Ltd. (Beijing, China) and confirmed by high-performance liquid chromatography by the Research and Engineering Center for Natural Medicine, Xi'an Jiaotong University (Xi'an, China). L-15 medium was obtained from Gibco (Thermo Fisher Scientific, Inc., Waltham, MA, USA). Fetal bovine serum was purchased from Hyclone (GE Healthcare Life Sciences, Logan, UT, USA). Trypsin was purchased from Amresco, LLC (Solon, $\mathrm{OH}, \mathrm{USA}$ ). IL-1 $\beta$ was purchased from PeproTech, Inc. (Rocky Hill, NJ, USA). Ethylenediamine tetra-acetic acid (EDTA) and 1-(4,5-dimethylthiazol-2-yl)-3,5-diphenylformazan (MTT) were purchased from Sigma-Aldrich (Merck KGaA, Darmstadt, Germany). Griess reagent was purchased from Nanjing Jiancheng Bioengineering Institute (Nanjing, China). The enzyme-linked immunosorbent assay (ELISA) kit for human IL-6 (cat. no. D6050) was purchased from R\&D Systems, Inc. (Minneapolis, MN, USA). Antibodies against COX-2 (cat. no. 12375-1-AP), MMP-13 (cat. no. 18165-1-AP), collagen II (cat. no. 15943-1-AP), NF-кB (cat. no. 10745-1-AP)

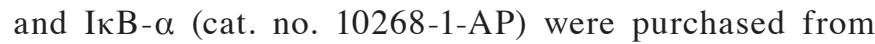
ProteinTech, Inc. (Rosemont, IL, USA) Antibodies against phosphorylated (p)-NF- $\kappa \mathrm{B}$ (cat. no. 3033) and $\mathrm{p}-\mathrm{I} \kappa \mathrm{B}-\alpha$ (cat. no. 2859) were purchased from Cell Signaling Technology, Inc. (Danvers, MA, USA). PGE $_{2}$ rabbit polyclonal antibody (cat. no. ab2318) and iNOS rabbit monoclonal antibody (cat. no. ab178945) were purchased from Abcam (Cambridge, MA, USA). Rabbit anti-GAPDH (cat. no. PA1-987), bicinchoninic acid (BCA) protein assay reagent kit and Pierce enhanced chemiluminescent (ECL) Plus Substrate were purchased from Pierce (Thermo Fisher Scientific, Inc.).

Cell culture. Human SW-1353 chondrocytes were purchased from the Shanghai Institute of Cell Biology, the Chinese Academy of Sciences (Shanghai, China) and cultured in L-15 supplemented with $10 \%$ fetal bovine serum, $100 \mathrm{U} / \mathrm{ml}$

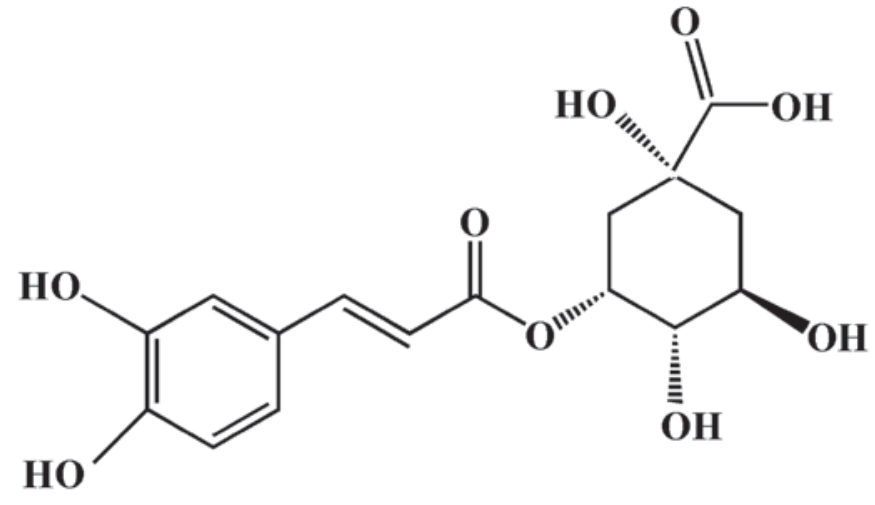

Figure 1. Chemical structure of chlorogenic acid.

penicillin and, $100 \mu \mathrm{g} / \mathrm{ml}$ streptomycin. Cells were incubated in a humidified incubator in an atmosphere containing $5 \% \mathrm{CO}_{2}$ at $37^{\circ} \mathrm{C}$. The culture medium was replaced every 3 days.

Cell viability assay. To evaluate the cytotoxic effects of CGA, cell viability was assessed using the MTT assay. Exponentially growing SW-1353 cells were plated into 96-well plates ( $2 \times 10^{6}$ cells $\left./ \mathrm{ml}\right)$ and cultivated overnight. The following day, CGA $(31.25,62.5,125,250,500$ or $1,000 \mu \mathrm{g} / \mathrm{ml})$, or various concentrations of CGA along with IL-1 $\beta(10 \mathrm{ng} / \mathrm{ml})$, was added to the cells, which were incubated for $48 \mathrm{~h}$ at $37^{\circ} \mathrm{C}$. The control cells received an equal amount of dimethyl sulfoxide (DMSO). Following removal of the medium, $180 \mu \mathrm{l}$ serum-free medium and $20 \mu \mathrm{l}$ MTT $(5 \mathrm{mg} / \mathrm{ml})$ was added to each well, and the plates were incubated at $37^{\circ} \mathrm{C}$ for $4 \mathrm{~h}$. The supernatants were replaced with $150 \mu \mathrm{l}$ DMSO to dissolve the crystals, the plates were agitated for $10 \mathrm{~min}$, and the absorbance was measured at $490 \mathrm{~nm}$ using a microplate reader (Bio-Rad Laboratories, Inc., Hercules, CA, USA). Survival was calculated according to the formula: Survival $=\mathrm{OD}_{\text {test }} / \mathrm{OD}_{\text {control }}$, where $\mathrm{OD}$ indicates optical density.

NO assay. NO production was assessed spectrophotometrically via the determination of nitrite concentrations in the cell culture supernatant using Griess reagent. SW-1353 chondrocytes $\left(2 \times 10^{6}\right.$ cell $\left./ \mathrm{ml}\right)$ were pretreated with various concentrations of CGA $(50,100,200$ or $500 \mu \mathrm{g} / \mathrm{ml})$ for $24 \mathrm{~h}$, and were subsequently exposed to IL-1 $\beta(10 \mathrm{ng} / \mathrm{ml})$ for $24 \mathrm{~h}$ at $37^{\circ} \mathrm{C}$. After $24 \mathrm{~h}$ the supernatants were collected. Each supernatant was mixed with an equal volume of Griess reagent $(150 \mu \mathrm{l})$ and incubated for $5 \mathrm{~min}$ at room temperature. Absorbance was subsequently determined at $540 \mathrm{~nm}$. Sodium nitrite was used to prepare the standard curve.

ELISA detection of IL-6 production. SW-1353 chondrocytes $\left(2 \times 10^{6}\right.$ cell $\left./ \mathrm{ml}\right)$ were pretreated with various concentrations of CGA $(50,100,200$ or $500 \mu \mathrm{g} / \mathrm{ml})$ for $24 \mathrm{~h}$, after which the cells were stimulated with IL-1 $\beta(10 \mathrm{ng} / \mathrm{ml})$ for $24 \mathrm{~h}$ at $37^{\circ} \mathrm{C}$. The amount of IL- 6 secreted into the culture medium was measured using a commercially available IL-6-specific ELISA kit according to the manufacturer's protocol.

Western blot analysis. SW-1353 chondrocytes $\left(2 \times 10^{6}\right.$ cells $\left./ \mathrm{ml}\right)$ were seeded and cultured in 6 -well plates. The cells were 

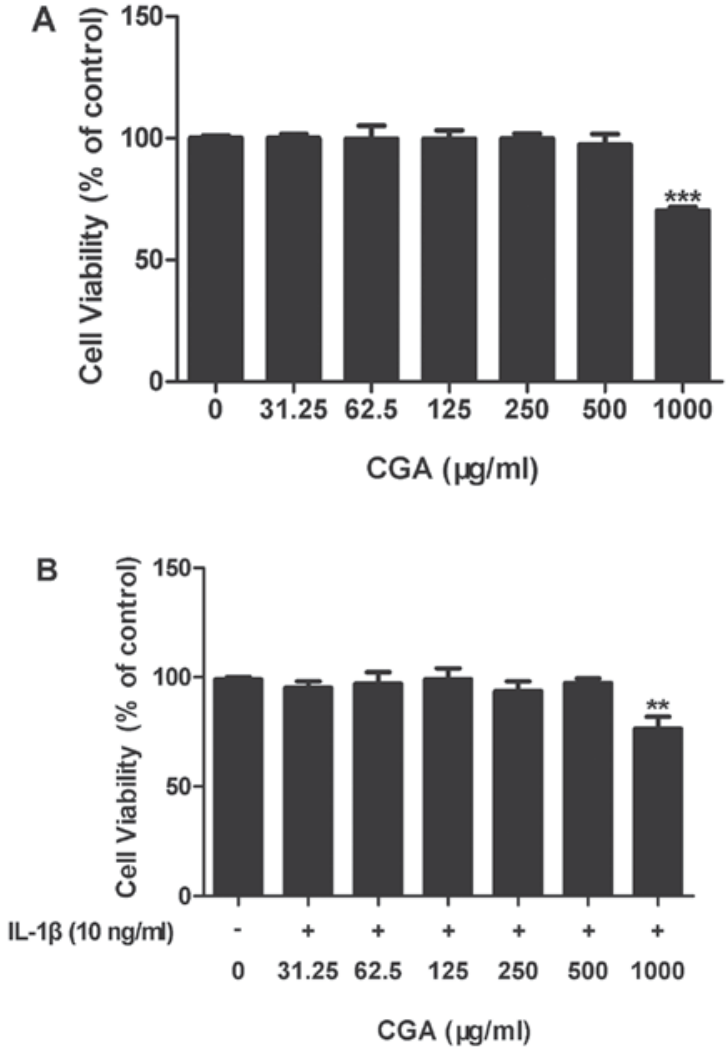

Figure 2. Effects of CGA and/or IL-1 $\beta$ on the viability of human SW-1353 chondrocytes. (A) Chondrocytes were treated with CGA $(31.25,62.5,125$, 250,500 , or $1,000 \mu \mathrm{g} / \mathrm{ml}$ ) alone for $48 \mathrm{~h}$. (B) Chondrocytes were treated with CGA $(31.25,62.5,125,250,500$ or $1,000 \mu \mathrm{g} / \mathrm{ml})$ and IL-1 $\beta(10 \mathrm{ng} / \mathrm{ml})$ for $48 \mathrm{~h}$. Values are expressed as the mean \pm standard error of the mean $(\mathrm{n}=3) .{ }^{* *} \mathrm{P}<0.01 ;{ }^{* * * *} \mathrm{P}<0.001$ vs. the control group. CGA, chlorogenic acid; IL, interleukin.

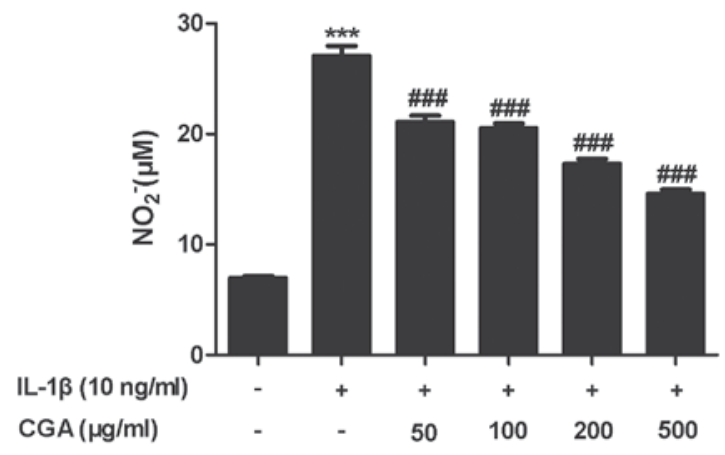

Figure 3. Effects of CGA on IL-1 $\beta$-induced NO production in human SW-1353 chondrocytes. Chondrocytes were pretreated with CGA $(50,100$, 200 or $500 \mu \mathrm{g} / \mathrm{ml})$ for $24 \mathrm{~h}$ followed by exposure to IL- $1 \beta(10 \mathrm{ng} / \mathrm{ml})$ for $24 \mathrm{~h}$ NO production was assessed by the Griess reaction. Values are presented as the mean \pm standard error of the mean. ${ }^{* * *} \mathrm{P}<0.05$ vs. the control group;

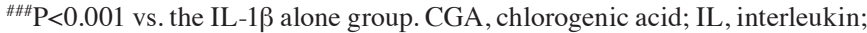
$\mathrm{NO}$, nitric oxide.

pretreated with CGA (50 or $200 \mu \mathrm{g} / \mathrm{ml}$ ) for $24 \mathrm{~h}$ at $37^{\circ} \mathrm{C}$, after which the cells were exposed to IL-1 $\beta(10 \mathrm{ng} / \mathrm{m})$ for $30 \mathrm{~min}$. Total proteins were isolated using lysis buffer $[50 \mathrm{mM}$ Tris- $\mathrm{HCl}$ (pH 7.5), $150 \mathrm{mM} \mathrm{NaCl}, 1 \mathrm{mMEDTA}, 20 \mathrm{mM} \mathrm{NaF}, 0.5 \% \mathrm{NP}-40$, $1 \%$ Triton, $1 \%$ protease inhibitor and phosphatase inhibitor cocktail]. Concentrations were determined using a BCA Protein
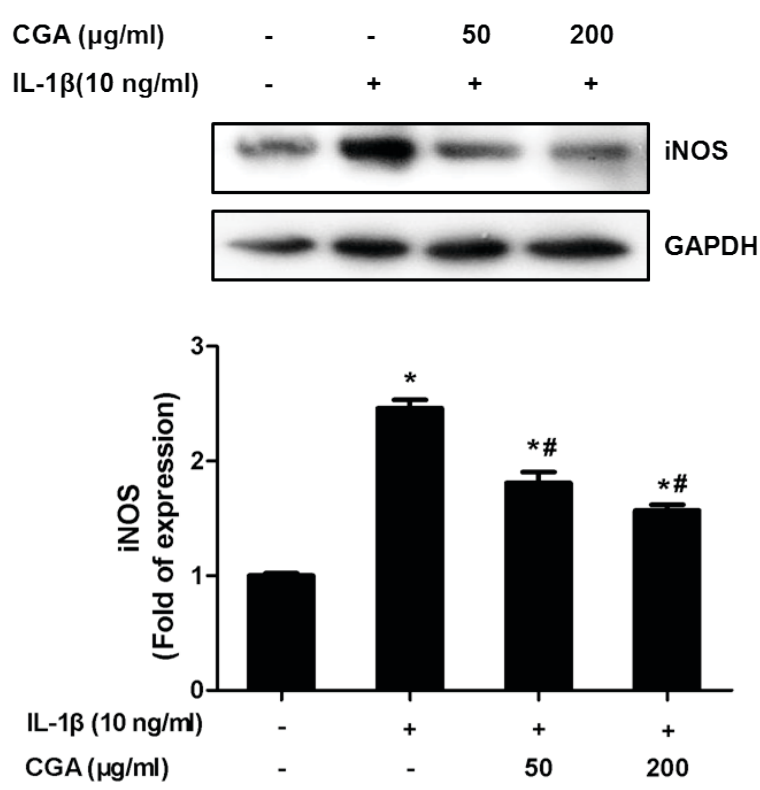

Figure 4. Effects of CGA on IL-1 1 -induced protein expression of iNOS in human SW-1353 chondrocytes. Chondrocytes were pretreated with CGA (50 or $200 \mu \mathrm{g} / \mathrm{ml})$ for $24 \mathrm{~h}$, followed by incubation with IL- $1 \beta(10 \mathrm{ng} / \mathrm{ml})$ for $30 \mathrm{~min}$. The expression of iNOS was determined by western blot analysis. The data represents band intensity compared with untreated samples, GAPDH was used for normalization. Data are presented as the mean \pm standard error of the mean. "P<0.05 vs. the control group; ${ }^{~} \mathrm{P}<0.05$ vs. the IL-1 $\beta$ alone group. CGA, chlorogenic acid; IL, interleukin; iNOS, inducible nitric oxide synthase.

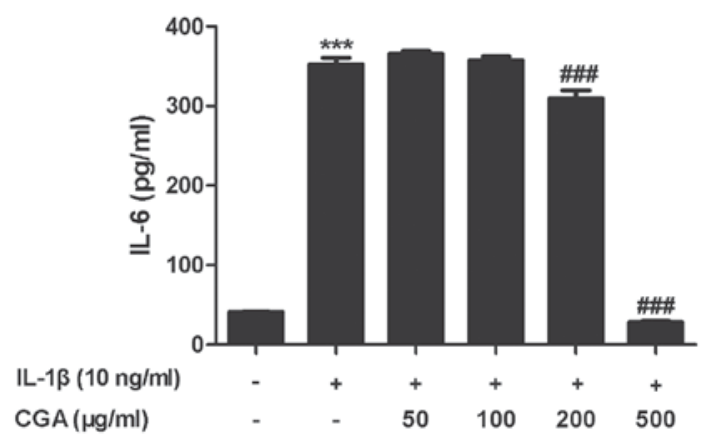

Figure 5. Effects of CGA on the levels of IL-6 from IL-1 $\beta$-stimulated SW-1353 chondrocytes. Cells were incubated with CGA $(50,100,200$ or $500 \mu \mathrm{g} / \mathrm{ml})$ for $24 \mathrm{~h}$ prior to exposure to IL-1 $\beta(10 \mathrm{ng} / \mathrm{ml})$ for $24 \mathrm{~h}$. The levels of IL- 6 were measured by ELISA. Data are presented as the mean \pm standard error of the mean. ${ }^{* * *} \mathrm{P}<0.05$ vs. the control group; ${ }^{\# \# \#} \mathrm{P}<0.001$ vs. the IL-1 $\beta$ alone group. CGA, chlorogenic acid; IL, interleukin.

Quantification kit. The proteins (30 $\mu \mathrm{g} / \mathrm{sample})$ were then separated on different percentages of SDS-polyacrylamide gel (6-10\%) and were transferred onto polyvinylidene difluoride membranes. Nonspecific sites were blocked with Tris-buffered saline $0.1 \%$ Tween-20 (TBST) plus 5\% nonfat dry milk for $2 \mathrm{~h}$ at room temperature, and the membranes were then incubated with primary antibodies (1:1,000 dilution) in 5\% skim milk overnight at $4^{\circ} \mathrm{C}$. The blots were subsequently washed three times with TBST, and incubated with horseradish peroxidase-linked secondary antibodies (1:15,000 dilution; cat. no. 31463; Pierce; Thermo Fisher Scientific, Inc.) for $2 \mathrm{~h}$ 
A
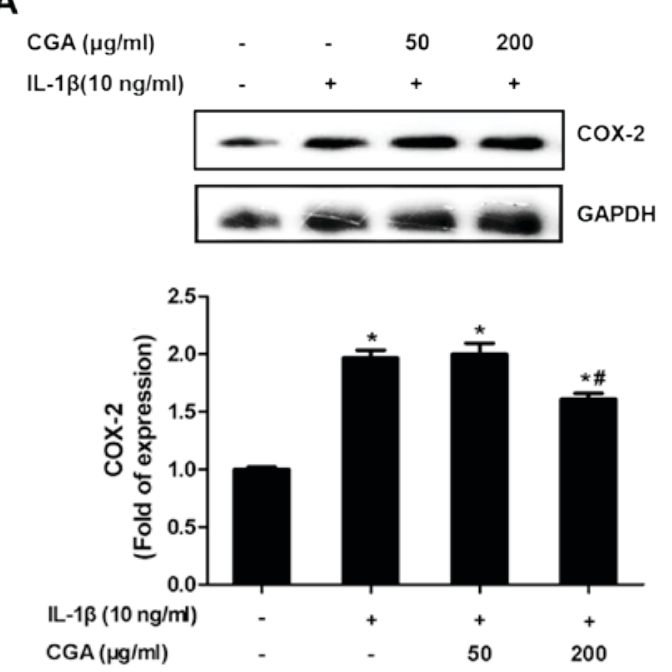

B
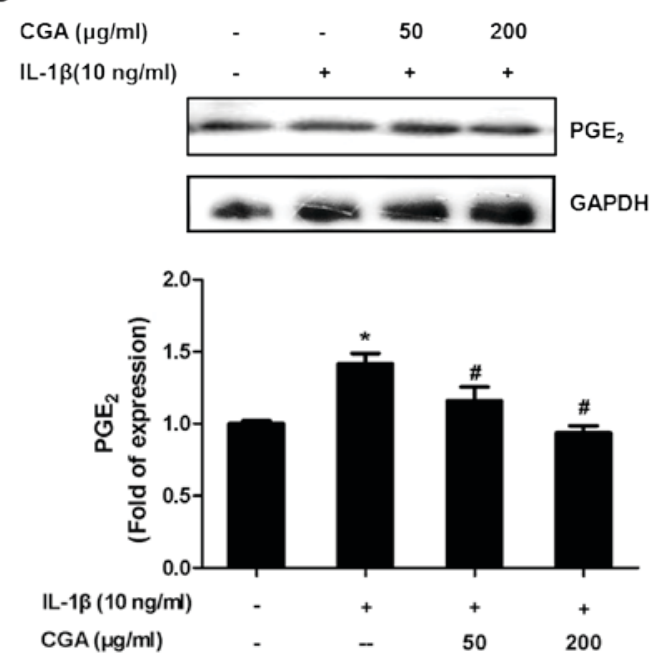

Figure 6. Effects of CGA on the expression of COX-2 and $\mathrm{PGE}_{2}$ from human $\mathrm{SW}-1353$ chondrocytes. Chondrocytes (2x10 6 cells/ml) were treated with CGA $(50$ or $200 \mu \mathrm{g} / \mathrm{ml})$ for $24 \mathrm{~h}$ followed by IL-1 $\beta$ (10 $\mathrm{ng} / \mathrm{ml})$ treatment for $30 \mathrm{~min}$. The expression levels of (A) COX-2 and (B) PGE 2 were determined by western blot analysis. Data are presented as the mean \pm standard error of the mean. ${ }^{*} \mathrm{P}<0.05$ vs. the control group; ${ }^{*} \mathrm{P}<0.05$ vs. the IL-1 $\beta$ alone group. CGA, chlorogenic acid; IL, interleukin; COX-2, cyclooxygenase 2; $\mathrm{PGE}_{2}$, prostaglandin $\mathrm{E}_{2}$.

at room temperature, and washed three further times with TBST. Protein bands were detected using a Pierce ECL Plus Substrate. GAPDH band intensity was used as internal control to normalize protein expression levels. The optical density was measured using Quantity One 1-D Analysis software (version 4.4; Bio-Rad Laboratories, Inc.).

Statistical analysis. All results were presented as the mean \pm standard error of the mean of $\geq 3$ independent experiments for each test. Differences among the various groups were assessed by one-way analysis of variance followed by Dunnett's test. Statistical analyses were performed using SPSS v. 12.0 software (SPSS, Inc., Chicago, IL, USA). P<0.05 was considered to indicate a statistically significant difference.

\section{Results}

Effects of CGA and/or IL-1 $\beta$ on human SW-1353 chondrocyte cell viability. An MTT assay was used to determine the effects of CGA on the cell viability of IL-1 $\beta$-induced human SW-1353 chondrocytes. The results indicated that CGA was cytotoxic to human SW-1353 chondrocytes at a concentration of $1,000 \mu \mathrm{g} / \mathrm{ml}$; however, cell viability in cells treated with up to $500 \mu \mathrm{g} / \mathrm{ml} \mathrm{CGA} \mathrm{was} \mathrm{not} \mathrm{significantly} \mathrm{different} \mathrm{from} \mathrm{the}$ control cells, with or without IL-1 $\beta$ stimulation (Fig. 2). Based on these results, the following experiments were conducted using CGA at concentrations $\leq 500 \mu \mathrm{g} / \mathrm{ml}$.

Effects of CGA on IL-1 $\beta$-stimulated NO production and iNOS expression in human $S W-1353$ chondrocytes. NO serves a pivotal role in OA progression. The results of the viability assay indicated that treatment with $500 \mu \mathrm{g} / \mathrm{ml} \mathrm{CGA} \mathrm{for} 48 \mathrm{~h}$ was not cytotoxic; therefore, the inhibitory effects of CGA $(50,100,200$ and $500 \mu \mathrm{g} / \mathrm{ml})$ on NO release in stimulated SW-1353 chondrocytes were examined. NO production was significantly enhanced following IL-1 $\beta$ activation for $24 \mathrm{~h}$, and pretreatment with CGA significantly diminished the IL-1 $\beta$-induced NO release in a concentration-dependent manner (Fig. 3). NO synthesis is predominantly catalyzed by iNOS; therefore, iNOS expression in SW-1353 chondrocytes was investigated. Consistent with the aforementioned results, CGA was able to inhibit IL-1 $\beta$-induced iNOS protein expression (Fig. 4).

Effects of CGA on the expression of IL-6 in IL-1 $\beta$-stimulated $S W-1353$ chondrocytes. To evaluate the effects of CGA on IL-6 production in human SW-1353 chondrocytes, IL-6 secretion was examined by ELISA. Human SW-1353 chondrocytes were pretreated with CGA for $24 \mathrm{~h}$ and then stimulated with IL-1 $\beta$ for $24 \mathrm{~h}$. IL-6 secretion from human SW-1353 chondrocytes was stimulated by IL- $1 \beta$ treatment, and this was reduced by treatment with CGA (Fig. 5). The observed alterations occurred in a concentration-dependent manner.

Inhibitory effects of CGA on COX-2 and PGE $\mathrm{C}_{2}$ expression in $I L-1 \beta$-stimulated $S W-1353$ chondrocytes. To evaluate whether CGA affected the levels of COX-2 and $\mathrm{PGE}_{2}$ in IL-1 $\beta$-induced SW-1353 chondrocytes, the protein expression levels of COX-2 and $\mathrm{PGE}_{2}$ were investigated by western blot analysis (Fig. 6). The results indicated that CGA significantly diminished IL-1 $\beta$-stimulated expression of COX-2 and $\mathrm{PGE}_{2}$, thus suggesting that CGA may inhibit the synthesis of $\mathrm{PGE}_{2}$ by influencing the enzymatic activity of COX-2.

Inhibitory effects of CGA on collagen II and MMP-13 expression in IL-1 $\beta$-stimulated $S W-1353$ chondrocytes. Protein expression levels of collagen II and MMP-13 were examined using western blot analysis (Fig. 7). As expected, CGA significantly diminished IL-1 $\beta$-induced MMP-13 protein expression, and markedly reversed the downregulation of collagen II expression in IL-1 $\beta$-stimulated SW-1353 chondrocytes. 
A
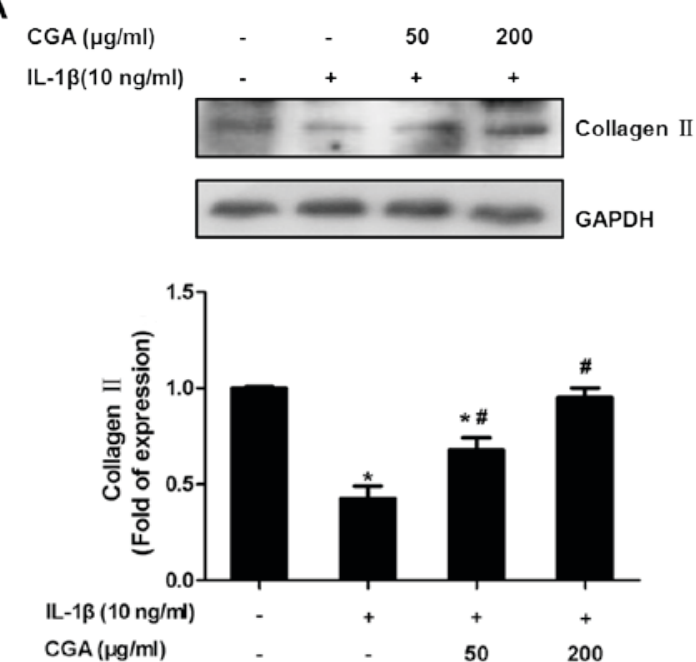

B
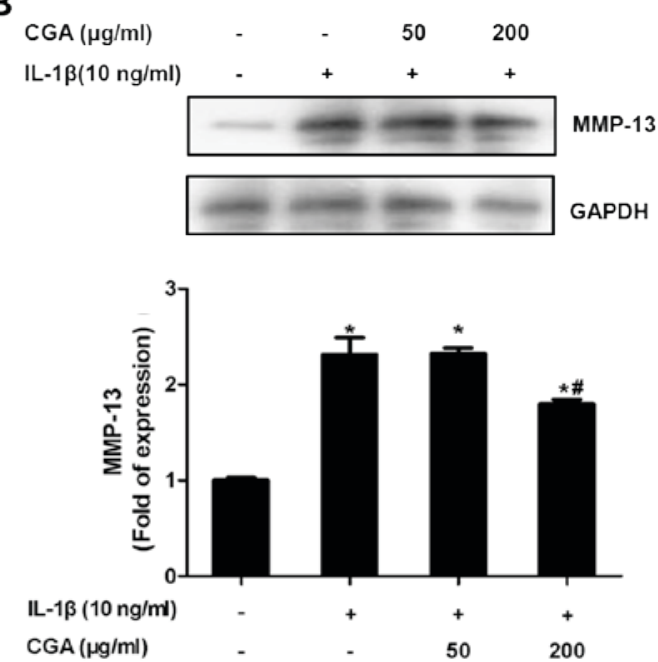

Figure 7. Effects of CGA on the expression of collagen II and MMP-13 from IL-1 1 -stimulated SW- 1353 chondrocytes. Chondrocytes ( $2 \times 10^{6}$ cells $\left./ \mathrm{ml}\right)$ were treated with CGA (50 or $200 \mu \mathrm{g} / \mathrm{ml}$ ) for $24 \mathrm{~h}$, and IL-1 $\beta$ (10 ng/ml) was added for $30 \mathrm{~min}$. The expression levels of (A) collagen II and (B) MMP-13 were analyzed by western blot analysis. Data are presented as the mean \pm standard error of the mean. ${ }^{*} \mathrm{P}<0.05$ vs. the control group; ${ }^{\#} \mathrm{P}<0.05$ vs. the IL-1 $\beta$ alone group. CGA, chlorogenic acid; IL, interleukin; MMP, matrix metalloproteinase.

A

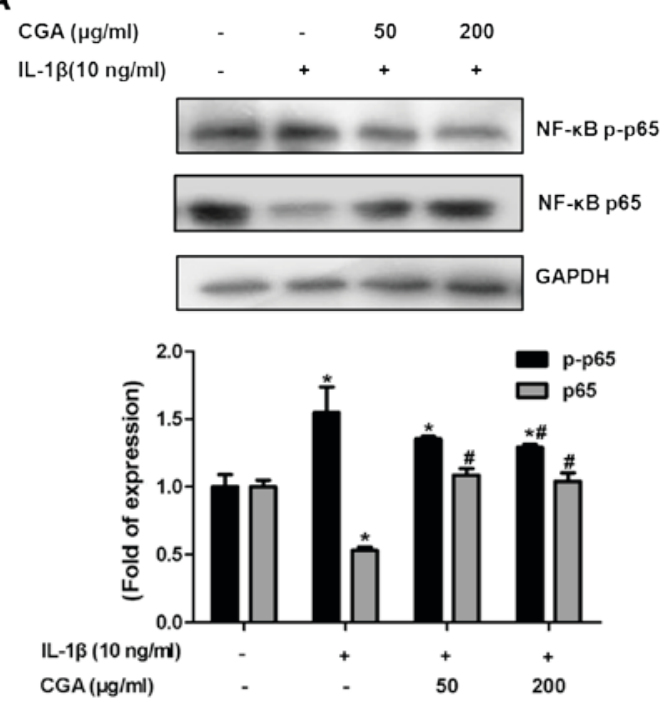

B

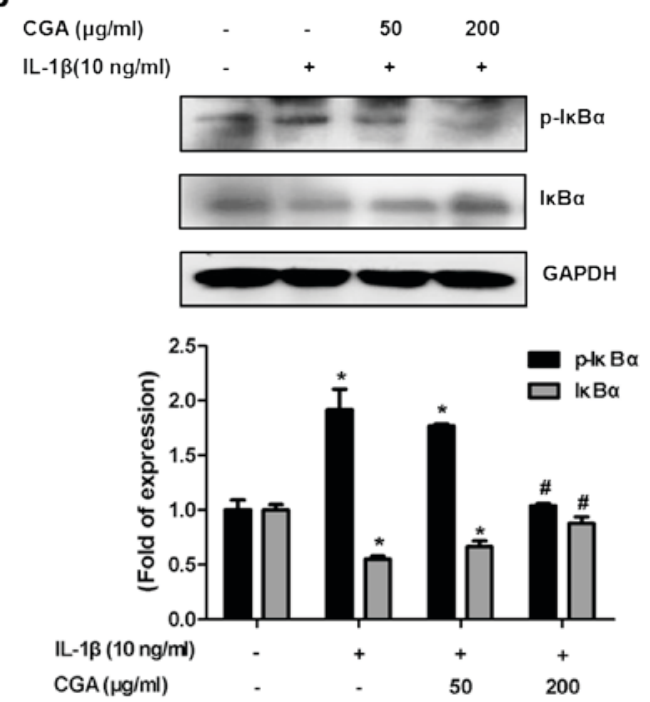

Figure 8. Effects of CGA on the I $\kappa \mathrm{B} \alpha / \mathrm{NF}-\kappa \mathrm{B}$ signaling pathway from IL-1 $\beta$-stimulated SW-1353 chondrocytes. Chondrocytes $\left(2 \times 10^{6}\right.$ cells/ml) were pretreated with CGA $(50$ or $200 \mu \mathrm{g} / \mathrm{ml})$ for $24 \mathrm{~h}$, followed by incubation with IL-1 $\beta(10 \mathrm{ng} / \mathrm{ml})$ for 30 min. Protein levels of (A) NF- $\kappa \mathrm{B}$ p65 and NF- $\kappa \mathrm{B}$ p-p65 and (B) I $\kappa \mathrm{B} \alpha$ and $\mathrm{p}-\mathrm{I} \kappa \mathrm{B} \alpha$ were examined by western blot analysis. Data are presented as the mean \pm standard error of the mean. * $\mathrm{P}<0.05$ vs. the control group; ${ }^{\#} \mathrm{P}<0.05$ vs. the IL-1 $\beta$ alone group. CGA, chlorogenic acid; IL, interleukin; NF- $\kappa \mathrm{B}$, nuclear factor $\kappa \mathrm{B}$; I $\mathrm{I} \mathrm{B} \alpha$, inhibitor- $\kappa \mathrm{B} \alpha$; $\mathrm{p}$, phosphorylated.

Effects of CGA on the I $\mathrm{B} B \alpha / N F-\kappa B$ signaling pathway in IL-1 $\beta$-stimulated $S W-1353$ chondrocytes. The NF- $\kappa \mathrm{B}$ signal transduction pathway serves vital roles in cartilage degradation and the inflammatory response. To investigate the effects of CGA-mediated inflammatory response inhibition on IL-1 $\beta$-stimulated chondrocytes, NF- $\kappa \mathrm{B}$ and its inhibitory protein $\mathrm{I} \kappa \mathrm{B} \alpha$ were detected. Western blot analysis was used to detect the levels of $\mathrm{NF}-\kappa \mathrm{B}$ p65 phosphorylation and $\mathrm{I} \kappa \mathrm{B}$ degradation. IL-1 $\beta$ stimulation resulted in the phosphorylation of $\mathrm{I} \kappa \mathrm{B} \alpha$ and $\mathrm{NF}-\kappa \mathrm{B}$ p65, whereas CGA reversed this effect (Fig. 8). These results indicated that the NF- $\kappa \mathrm{B}$ signal transduction pathway may be inhibited by CGA in IL-1 $\beta$-stimulated SW-1353 chondrocytes.

\section{Discussion}

$\mathrm{OA}$ is the most prevalent joint disease, and there are currently no effective treatments to limit disease progression. Inflammation has been recognized as an important process in the pathogenesis of OA. Proinflammatory cytokines, including TNF- $\alpha$ and IL-1, become activated during OA progression, and this induces inflammatory responses and cartilage destruction (3). Commonly-used pharmacological treatments, such as oral non-steroidal anti-inflammatory drugs, for the treatment of patients with $\mathrm{OA}$, are often associated with serious adverse effects (22). Therefore, plant-derived agents that possess anti-inflammatory activity and low toxicity are 
more frequently being employed as a therapeutic option in OA (23). CGA, which is a bioactive phenolic acid component isolated from plants, displays anti-inflammatory activity and has been recommended for the treatment of OA (24). The present study aimed to determine the anti-inflammatory and cartilage-protective effects of CGA on IL-1 $\beta$-stimulated SW-1353 chondrocytes.

IL-1 $\beta$ is an important proinflammatory cytokine released by activated synoviocytes or chondrocytes, which serves an important role in the progression of OA (25). Several studies have indicated that IL-1 $\beta$ upregulates NO production via stimulation of iNOS activity, and elevates the COX2-mediated expression of $\mathrm{PGE}_{2}$. In addition, IL-1 $\beta$ induces the expression of other proinflammatory cytokines, including IL-6 and IL-17, and stimulates matrix remodeling via the regulation of MMPs, resulting in the degradation of aggrecan and other matrix constituents $(26,27)$. Therefore, IL-1 $\beta$-stimulated SW-1353 cells have been employed as an in vitro cellular model of OA $(8,28)$.

$\mathrm{NO}$ is produced from the amino acid L-arginine by the enzymatic action of iNOS, which is induced by inflammatory stimuli, indicating that this proinflammatory mediator could contribute to OA disease (29). In the present study, statistical analysis revealed that CGA markedly decreased iNOS expression and NO production from IL-1 $\beta$-stimulated SW-1353 chondrocytes in a concentration-dependent manner, thus suggesting that CGA may possess an anti-inflammatory role via the regulation of NO synthesis.

$\mathrm{PGE}_{2}$ is another key inflammatory mediator; $\mathrm{PGE}_{2}$ is synthesized from arachidonic acid via the stimulation of $\mathrm{COX}-2$ during the inflammatory response. COX-2 has been recognized as an inducible or pathological enzyme that participates in the inflammatory response by facilitating $\mathrm{PGE}_{2}$ generation, and promotes the inflammatory cytokine-induced metabolic imbalance of cartilage proteoglycans, thereby advancing arthritis (30,31). IL-6 has been considered as another crucial cytokine involved in the inflammatory response. The present study explored the anti-inflammatory role of CGA, and the results indicated that $\mathrm{CGA}$ may inhibit the protein expression of $\mathrm{PGE}_{2}$ and COX-2, and the secretion of IL-6, in human SW-1353 chondrocytes in a concentration-dependent manner.

Cartilage destruction is a fundamental disease-progression process that occurs in OA. Therefore, the role CGA serves in abrogating this process was further explored. Chondrocytes are the solitary cellular components of cartilage; under normal conditions, these cells maintain the ECM, and balance anabolic and catabolic metabolism (32). The human SW-1353 chondrosarcoma line has been employed in several studies as an in vitro model to investigate the molecular mechanisms and pharmacological treatments for OA, due to its similarity with human OA chondrocytes $(7,33)$. MMPs are a family of zinc-dependent proteases that serve important roles in cartilage ECM degradation and maintenance, and are upregulated in pathophysiological inflammatory conditions (34). MMP upregulation results in the erosion of articular cartilage and thus participates in OA progression. In particular, the collagenase MMP-13 preferentially cleaves type II collagen, which is the predominant collagen involved in the structural and functional integrity of cartilage (35). The present study explored whether CGA was able to exert chondroprotective effects via MMP suppression in chondrocytes. The results indicated that
CGA reduced MMP-13 expression and reversed the reduction of collagen II induced by IL-1 $\beta$, compared with the untreated group from human SW-1353 chondrocytes.

$\mathrm{NF}-\kappa \mathrm{B}$ is a cytokine-induced transcription factor that serves an important role in regulating the expression of various genes, including numerous proinflammatory cytokines, adhesion molecules and proteases in arthritis, such as MMPs, $\mathrm{PGE}_{2}$, NO and IL-6 (9); several of the IL-1 $\beta$-induced inflammatory mediators in chondrocytes are regulated by the $\mathrm{NF}-\kappa \mathrm{B}$ signaling pathway (36). In light of the role of NF- $\mathrm{NB}$ in $\mathrm{OA}$ progression, blocking its activity may have therapeutic advantages. The p65 subunit of NF- $\mathrm{BB}$ is normally sequestered into the cytoplasm under resting conditions, and is blocked by IкB $\alpha$ proteins (37). During inflammation, $\mathrm{I} \kappa \mathrm{B} \alpha$ proteins are phosphorylated and degraded by the proteasome, the NF- $\kappa \mathrm{B}$ p65 subunit is released and phosphorylated and then translocated into the nucleus, where it binds to DNA promoter regions and activates the transcription of target genes (38). In the present study, CGA intervention was able to reduce IкB $\alpha$ degradation and consequently decrease phosphorylated-NF- $\mathrm{B}$ p 65 levels in human SW-1353 chondrocytes, and this occurred in a concentration-dependent manner. These results indicated that the protective and anti-inflammatory effects of CGA on human SW-1353 chondrocytes may occur via the NF- $\kappa \mathrm{B}$ pathway.

In conclusion, the present study demonstrated the in vitro anti-inflammatory and cartilage-protective role of CGA. The underlying mechanism appeared to involve the inhibition of COX-2, PGE 2 , iNOS, NO, IL-6 and MMP-13. Furthermore, IL-1 $\beta$-induced collagen II destruction was abrogated via the inhibition of $\mathrm{I} \kappa \mathrm{B} \alpha / \mathrm{NF}-\kappa \mathrm{B}$ activation. These results suggested that CGA may be considered a novel therapeutic candidate against arthritic diseases. Future studies should fully clarify the molecular mechanisms underlying the effects of CGA on chondrocytes, as there may be additional signaling pathways involved. In vivo investigations of CGA in animals and humans are required to further investigate the potential of CGA in the clinical management of OA.

\section{Acknowledgements}

The present study was supported by the Research Foundation of Xi'an Hong-Hui Hospital (grant no. YJ2014016).

\section{References}

1. Chang CC, Hsieh MS, Liao ST, Chen YH, Cheng CW, Huang PT, Lin YF and Chen CH: Hyaluronan regulates PPAR $\gamma$ and inflammatory responses in IL-1 $\beta$-stimulated human chondrosarcoma cells, a model for osteoarthritis. Carbohydr Polym 90: 1168-1175, 2012.

2. Karlsen TA, de Souza GA, Ødegaard B, Engebretsen L and Brinchmann JE: microRNA-140 inhibits inflammation and stimulates chondrogenesis in a model of interleukin $1 \beta$-induced osteoarthritis. Mol Ther Nucleic Acids 5: e373, 2016.

3. Fernandes JC, Martel-Pelletier J and Pelletier JP: The role of cytokines in osteoarthritis pathophysiology. Biorheology 39: 237-246, 2002.

4. Wang K, Xu J, Hunter DJ and Ding C: Investigational drugs for the treatment of osteoarthritis. Expert Opin Investig Drugs 24: 1539-1556, 2015.

5. Siebuhr AS, Bay-Jensen AC, Jordan JM, Kjelgaard-Petersen CF, Christiansen C, Abramson SB, Attur M, Berenbaum F, Kraus V and Karsdal MA: Inflammation (or synovitis)-driven osteoarthritis: An opportunity for personalizing prognosis and treatment? Scand J Rheumatol 45: 87-98, 2016. 
6. Klatt AR, Klinger G, Neumüller O, Eidenmuller B, Wagner I, Achenbach T, Aigner T and Bartnik E: TAK1 downregulation reduces IL-1beta induced expression of MMP13, MMP1 and TNF-alpha. Biomed Pharmacother 60: 55-61, 2006

7. Pattoli MA, MacMaster JF, Gregor KR and Burke JR: Collagen and aggrecan degradation is blocked in interleukin-1-treated cartilage explants by an inhibitor of IkappaB kinase through suppression of metalloproteinase expression. J Pharmacol Exp Ther 315: 382-388, 2005

8. Ma Z, Wang Y, Piao T and Liu J: Echinocystic acid inhibits IL-1 $\beta$-induced COX-2 and iNOS expression in human osteoarthritis chondrocytes. Inflammation 39: 543-549, 2016.

9. Marcu KB, Otero M, Olivotto E, Borzi RM and Goldring MB NF-kappaB signaling: Multiple angles to target OA. Curr Drug Targets 11: 599-613, 2010.

10. Illing EA, Cho DY, Zhang S, Skinner DF, Dunlap QA, Sorscher EJ and Woodworth BA: Chlorogenic acid activates CFTR-mediated Cl- secretion in mice and humans: Therapeutic implications for chronic rhinosinusitis. Otolaryngol Head Neck Surg 153: 291-297, 2015.

11. Hu W, Guo T, Jiang WJ, Dong GL, Chen DW, Yang SL and Li HR Effects of ultrahigh pressure extraction on yield and antioxidant activity of chlorogenic acid and cynaroside extracted from flower buds of Lonicera japonica. Chin J Nat Med 13: 445-453, 2015.

12. Chen X, Sang X, Li S, Zhang S and Bai L: Studies on a chlorogenic acid-producing endophytic fungi isolated from Eucommia ulmoides Oliver. J Ind Microbiol Biotechnol 37: 447-454, 2010.

13. Pang C, Sheng YC, Jiang P, Wei H and Ji LL: Chlorogenic acid prevents acetaminophen-induced liver injury: The involvement of CYP450 metabolic enzymes and some antioxidant signals. J Zhejiang Univ Sci B 16: 602-610, 2015.

14. Ren S, Wu M, Guo J, Zhang W, Liu X, Sun L, Holyst R, Hou S, Fang Y and Feng X: Sterilization of polydimethylsiloxane surface with Chinese herb extract: A new antibiotic mechanism of chlorogenic acid. Sci Rep 5: 10464, 2015.

15. Shao P, Zhang JF, Chen XX and Sun PL: Microwave-assisted extraction and purification of chlorogenic acid from by-products of Eucommia Ulmoides Oliver and its potential anti-tumor activity. J Food Sci Technol 52: 4925-4934, 2015.

16. Ruifeng G, Yunhe F, Zhengkai W, Ershun Z, Yimeng L, Minjun Y, Xiaojing S, Zhengtao Y and Naisheng Z: Chlorogenic acid attenuates lipopolysaccharide-induced mice mastitis by suppressing TLR4-mediated NF- $\kappa \mathrm{B}$ signaling pathway. Eur J Pharmacol 729: 54-58, 2014.

17. Kang JW and Lee SM: Protective effects of chlorogenic acid against experimental reflux esophagitis in rats. Biomol Ther (Seoul) 22: $420-425,2014$

18. Zhang X, Huang H, Yang T, Ye Y, Shan J, Yin Z and Luo L: Chlorogenic acid protects mice against lipopolysaccharide-induced acute lung injury. Injury 41: 746-752, 2010.

19. Hwang SJ, Kim YW, Park Y, Lee HJ and Kim KW: Anti-inflammatory effects of chlorogenic acid in lipopolysaccharide-stimulated RAW 264.7 cells. Inflamm Res 63: 81-90, 2014.

20. Lee JH, Park JH, Kim YS and Han Y: Chlorogenic acid, a polyphenolic compound, treats mice with septic arthritis caused by Candida albicans. Int Immunopharmacol 8: 1681-1685, 2008.

21. Kwak SC, Lee C, Kim JY, Oh HM, So HS, Lee MS, Rho MC and $\mathrm{Oh} \mathrm{J}$ : Chlorogenic acid inhibits osteoclast differentiation and bone resorption by down-regulation of receptor activator of nuclear factor kappa-B ligand-induced nuclear factor of activated T cells c1 expression. Biol Pharm Bull 36: 1779-1786, 2013.

22. Chen YJ, Tsai KS, Chan DC, Lan KC, Chen CF, Yang RS and Liu SH: Honokiol, a low molecular weight natural product, prevents inflammatory response and cartilage matrix degradation in human osteoarthritis chondrocytes. J Orthop Res 32 573-580, 2014

23. Tsai CF, Wang KT, Chen LG, Lee CJ, Tseng SH and Wang CC: Anti-inflammatory effects of Vitis thunbergii var. taiwaniana on knee damage associated with arthritis. J Med Food 17: 479-486, 2014.
24. dos Santos MD, Almeida MC, Lopes NP and de Souza GE Evaluation of the anti-inflammatory, analgesic and antipyretic activities of the natural polyphenol chlorogenic acid. Biol Pharm Bull 29: 2236-2240, 2006

25. Shi J, Schmitt-Talbot E, DiMattia DA and Dullea RG: The differential effects of IL-1 and TNF-alpha on proinflammatory cytokine and matrix metalloproteinase expression in human chondrosarcoma cells. Inflamm Res 53: 377-389, 2004.

26. Sun Y, Zhou L, Lv D, Liu H, He T and Wang X: Poly(ADP-ribose) polymerase 1 inhibition prevents interleukin-1 $\beta$-induced inflammation in human osteoarthritic chondrocytes. Acta Biochim Biophys Sin (Shanghai) 47: 422-430, 2015.

27. Vincenti MP and Brinckerhoff CE: Early response genes induced in chondrocytes stimulated with the inflammatory cytokine interleukin-1beta. Arthritis Res 3: 381-388, 2001.

28. Wang Z, Ding L, Zhang S, Jiang T, Yang Y and Li R: Effects of icariin on the regulation of the OPG-RANKL-RANK system are mediated through the MAPK pathways in IL-1 $\beta$-stimulated human SW1353 chondrosarcoma cells. Int J Mol Med 34: 1720-1726, 2014

29. Tao R, Wang S, Xia X, Wang Y, Cao Y, Huang Y, Xu X, Liu Z, Liu P, Tang X, et al: Pyrroloquinoline quinone slows down the progression of osteoarthritis by inhibiting nitric oxide production and metalloproteinase synthesis. Inflammation 38: 1546-1555, 2015.

30. Fan HW, Liu GY, Zhao CF, Li XF and Yang XY: Differential expression of COX-2 in osteoarthritis and rheumatoid arthritis. Genet Mol Res 14: 12872-12879, 2015.

31. Yu SM and Kim SJ: The thymoquinone-induced production of reactive oxygen species promotes dedifferentiation through the ERK pathway and inflammation through the p38 and PI3K pathways in rabbit articular chondrocytes. Int J Mol Med 35: 325-332, 2015.

32. Zhao L, Ye J, Wu GT, Peng XJ, Xia PF and Ren Y: Gentiopicroside prevents interleukin-1 beta induced inflammation response in rat articular chondrocyte. J Ethnopharmacol 172: 100-107, 2015.

33. Petrella BL, Armstrong DA and Vincenti MP: CCAAT-enhancer-binding protein beta activation of MMP-1 gene expression in SW1353 cells: Independent roles of extracellular signal-regulated and p90/ribosomal S6 kinases. J Cell Physiol 226: 3349-3354, 2011.

34. Hu P, Chen W, Bao J, Jiang L and Wu L: Cordycepin modulates inflammatory and catabolic gene expression in interleukin-1beta-induced human chondrocytes from advanced-stage osteoarthritis: An in vitro study. Int J Clin Exp Pathol 7: 6575-6584, 2014.

35. Chen YJ, Chan DC, Lan KC, Wang CC, Chen CM, Chao SC, Tsai KS, Yang RS and Liu SH: PPAR $\gamma$ is involved in the hyperglycemia-induced inflammatory responses and collagen degradation in human chondrocytes and diabetic mouse cartilages. J Orthop Res 33: 373-381, 2015.

36. Wang SN, Xie GP, Qin CH, Chen YR, Zhang KR, Li X, Wu Q, Dong WQ, Yang J and Yu B: Aucubin prevents interleukin-1 beta induced inflammation and cartilage matrix degradation via inhibition of NF-kB signaling pathway in rat articular chondrocytes. Int Immunopharmacol 24: 408-415, 2015.

37. Qiu J, Yu L, Zhang X, Wu Q, Wang D, Wang X, Xia C and Feng H: Asiaticoside attenuates lipopolysaccharide-induced acute lung injury via down-regulation of $\mathrm{NF}-\kappa \mathrm{B}$ signaling pathway. Int Immunopharmacol 26: 181-187, 2015.

38. Wang QS, Xiang Y, Cui YL, Lin KM and Zhang XF: Dietary blue pigments derived from genipin, attenuate inflammation by inhibiting LPS-induced iNOS and COX-2 expression via the NF-kB inactivation. PLoS One 7: e34122, 2012. 